\title{
Intelligent Diagnostic Method for Ageing Analysis of Transformer
}

\author{
Anil Kumar Kori ${ }^{*}$, Arvind Kumar Sharma ${ }^{1}$, Ashok Kumar Singh Bhadoriya ${ }^{2}$ \\ ${ }^{1}$ Department of Electrical Engineering, Jabalpur Engineering College, Jabalpur, India \\ ${ }^{2}$ Rajiv Gandhi Technical University, Bhopal, India \\ Email: \{*akkori1, Arvindksharma_2000\}@rediffmail.com,dr.aksbhadoria@yahoo.co.in
}

Received February 14, 2011; revised April 28, 2011; accepted May 19, 2011

\begin{abstract}
The fuzzy method is proposed for ageing analysis of transformer. The fuzzy controller is used for various input and one output, strictly depends on the number of membership function and there rule base and the type of the defuzzification method. The ageing of transformers is influenced by short term and long term over loads, number and intensity of short circuits, incidence of lightning, and internal faults. The recent development of various techniques for detecting the incipient fault conditions have been improved to some extent; the life expectancy of transformers by resorting to corrective actions in time. The ageing behavior is likely to be different for different types of transformers. The life span of the transformer, thus depends initially on the design and quality of manufacture and later on service conditions and maintenance standard, these factors vary considerably and affect the useful span of service life which therefore needs to be taken into account for residual life assessment. During the natural ageing of transformers, the insulation of winding deteriorates. Cellulose insulation degrades due to heating or electrical breakdown which is dissolved in oil. Hence, the chemical analysis of the Transformer oil gives evidence of changes that are taking place in the winding insulation during operation. Deterioration in transformer cellulose decreases both its electrical and mechanical strength. In this paper a novel fuzzy based algorithm has been implemented on three samples of power transformer oil.
\end{abstract}

Keywords: Transformer Oil; Paper Insulation; Electrical Breakdown; Ageing Analysis; Fuzzy Logic Controller

\section{Introduction}

In power transformer paper ageing is a process involving both chemical and physical changes causing a loss of both mechanical and electrical strength. The moisture content in paper insulation is commonly determined from oil samples. Since oil paper moisture equilibrium is temperature dependent and takes a long time to be in equilibrium. Moreover, lots of transformers will operate at variable loading so it is not possible to reach ideal equilibrium for most of transformers. Hence, moisture measurement in oil sample generally gives in conclusive information. Direct acquisition of moisture in paper insulation is generally not accessible for inservice transformers [1,2]. The condition of oil-paper insulation system is the main diagnostic indicator that influences failure-free operation of transformers. Monitoring of such characteristics, which concern in the failure of machine is necessary when safe and reliable operation is required [3]. Selection of suitable diagnostic methods is the first important objective during the design of monitoring system. As the aging of transformer insulation system is affected mainly by changes of tem-

\footnotetext{
"Corresponding author.
}

perature and electrical operation characteristics, the observation of these characteristics is included in our monitoring system. [4]. Deterioration of paper and oil is caused by oxidation accelerated by high temperatures, air and moisture. The oil oxidation will lead to acids and paraoxides production. These compounds are introduced into the transformer oil. The main requirements of insulating oil are to provide insulation, to withstand electric stresses imposed in service as the oil has high dielectric strength and low dissipation factor, to transfer heat and to provide cooling [5]. Moisture and oxygen cause the oil and the paper insulation to decay much faster than the normal rate and form acid and sludge. Sludge settles on windings and inside the structure, causing transformer temperature rises. In experimental study on oil degradation is carried out under elevated temperature conditions. The effects of water and ageing (oxidation) on breakdown voltage of aged transformer oils are particularly studied. The oil must have viscosity and pour point that are sufficiently low to ensure that the oil circulation is not impaired at the most extreme low temperature conditions for the equipment. To meet the arc quenching function, the oil requires a combination of high dielectric strength, low viscosity and 
high flash point to provide sufficient nsulation and cooling to ensure arc is extinguished. The oil must have low acidity (neutralization value) to eliminate the risk of sludge formation and corrosion. The Breakdown Voltage should be sufficiently high to provide dielectric strength to prevent oil under electrical stresses. The oil must not contain levels of contamination by an individual metal. The density of oil has to be low enough to ensure that ice cannot float on the oil surfaces at very low temperatures and cause internal flashover. The Dielectric Dissipation Factor has to be sufficiently low to ensure that the dielectric losses are small and that the oil thus provides satisfactory insulating properties [6]. It is well known that the cellulosic insulation of power transformers deteriorates steadily in operation. The major cause for the deterioration is the thermal stress in conjunction with water, acids and oxygen. Only indirect methods are available for the assessment of the insulation condition of transformers in service. With these methods the oil is tested for by products from the aging process. These can reduce the effectiveness of cooling and cause general internal deterioration and eventual failure. The oil must have a low particle size and count and low fiber content as the presence of such contaminants, especially in the presence of moisture, can considerably reduce the electric strength [7]. The Pour Point is related to viscosity and needs to be low enough to ensure that oil flows satisfactorily under low temperature conditions. The oil must have low sulphur content to ensure the oil flows under all temperature (particularly low) conditions thus providing necessary cooling and arc quenching properties of insulating oil. The moisture must have low. The low dissipation factor and less number of particle maintains the breakdown strength of oil [8]. The fuzzy logic modeling and analysis has been carried out to get better asset's remnant life estimation. To estimate the age of a power transformer fuzzy logic based approach is useful [9]. Fuzzy system and neural network approach is used for analysis of transformer $[10,11]$. Section 2 describes required chemical and electrical tests have been performed on sampled oil for ageing analysis of power transformer. The rating of Power Transformer was $40 \mathrm{MVA}, 132 / 33 \mathrm{kV}$. Section 3 describes overviews of fuzzy logic, problem formulation and solution methodology. Section 4 describes Results and discussions. Section 5 gives conclusions.

\section{Brief Description of Tests to Be Performed}

\subsection{Moisture Content Analysis}

Deterioration in transformer cellulose decreases both its electrical and mechanical strength. In general, the greater the water content the more the mechanical strength reduces. Mineral oil has a very limited capacity to absorb moisture. Most of the water produced during ageing remains in the windings, reducing the insulation resistance of the transformer. It also reduces the transformer's ability to withstand the mechanical and electrical stresses that occur in operation additionally, high levels of moisture can effectively reduce the dielectric strength of the mineral oil. Over time this will result in outages and/or the necessary down rating of the transformer and ultimately could result in complete failure. While preparing this study we have used 831 KF Coulometer. The coulometric Karl Fischer titration is as version of the classical water determination method by Carl Fischer. The traditional method utilizes a methanoic solution of iodine, sulpher dioxide and a base as buffer. Several reactions run in the titration of water containing sample and can be summarized by the following overall equation:

$$
\begin{aligned}
& \mathrm{H}_{2} \mathrm{O}+\mathrm{I}_{2}+[\mathrm{RNH}] \mathrm{SO}_{3} \mathrm{CH}_{3}+2 \mathrm{RN} \\
\leftrightarrow & {[\mathrm{RNH}] \mathrm{SO}_{4} \mathrm{CH}_{3}+2[\mathrm{RNH}] }
\end{aligned}
$$

According to the above equation, $\mathrm{I}_{2}$ reacts quantitatively with $\mathrm{H}_{2} \mathrm{O}$.This chemical relation forms the basis of the water determination. In the coulometric Karl Fischer titration, the iodine needed is generated directly in the electrolyte by electrochemical means ("electronic buret”). The rigorously quantitative relationship between the electric charge and the amount of iodine generated is used for high-precision dispensing of the iodine. As the coulometer Karl Fischer is an absolute determination no titer need be determined. It is necessary only to ensure that the reaction which generates the iodine runs with $100 \%$ current efficiency. With the reagents available today this is always the case. The end point is indicated voltameterically by applying an alternating current of constant strength to strength to a double Pt electrode. This results in a voltage difference between the Pt wires of the indicator electrodes which is drastically lowered in the presence of minimal quantities of free Iodine. This fact is used to determine the end point of the titration.

\subsection{Analysis of Suspended Particles Size}

In case of deteriorated or waste oil their may be some dissolved particles. The larger the size and no of conducting particles decrease the break down voltage spectrex laser particle counter utilizes the principle of "near angle light scatter"; a revolving laser beam passes through the walls of a glass container of a flow-thru cell. When it is directed through a central "sensitive zone" the PC-2200 not only counts the particle in suspension, but tabulates their size as well.

\subsection{Acidity Analysis}

Acidity of oil is a measure of the acidic constituents in the oil. Its value, negligible in an unused oil, increase as a result of oxidative ageing and as a general guide for determining when an oil should be replaced or reclaimed, 
provided suitable rejection limits have been established and confirmation is received from other tests. Oil with high neutralization value affects the winding \& paper. Normally the transformer have uninhibited oil. Sometimes inhibited oil is used. The inhibitor works so that it breaks the chain reaction by which sludge and acid are produced. If sludge is produced in oil, the oil changes color and become darker and turbid. The sludge can be removed by means of filtration but if sludge formation has it would increase with time. The oil exchange should preferably be carried out when transformer is warm and oil viscosity is low. Transformer oils deteriorate with time. High operating temperatures, the presence of oxygen and water combined with the catalytic action of the materials within the transformer, result in oxidation and cracking of the oil. The by-products of oxidation are acidic and the longterm effect of these by-products results in an exponential increase in deterioration of the transformer and its oil. The resulting sludge build-up reduces the cooling effects of the oil driving the whole decay mechanism at an increasingly accelerated rate. New transformer oils contain practically no acids if properly refined. The acidity test measures the content of acids formed oxidation. The oxidation products polymerize to form sludge which then precipitates out. Acids react with metals on the surfaces inside the tank and form metallic soaps, another form of sludge. Sludging has been found to begin when the acid number reaches or exceeds $0.04 \mathrm{mg} \mathrm{KOH} / \mathrm{G}$, and 0.04 $\mathrm{mg} \mathrm{KOH} / \mathrm{G}$ is considered to be the normal service limit. New oil has a acid number of less than $0.05 \mathrm{mg} \mathrm{KOH} / \mathrm{G}$. The acid number (formerly referred to as neutralization number) equals the milligrams of $\mathrm{KOH}$ (potassium hydroxide) required to neutralize the acid contained in 1 gram of oil. For this study we have used 702 SM Titrino.

\subsection{Resistivity Test}

The resistivity of a liquid is a measure of its electrical insulating properties under conditions comparable to those of the test. High resistivity reflects low content of free ions and ion-forming particles and normally indicates a low concentration of conductive contaminants. These characteristics are very sensitive to the presence in the oil of soluble contaminants and ageing products. Resistivity is normally carried out at ambient temperature but useful additional information can be obtained if the test is carried out at ambient and a higher temperature such as 90 degrees Celsius. Unsatisfactory results at both temperatures indicate a greater extent of contamination than a poor value at the lower temperature only, and the oil is therefore less likely to be restored to a satisfactory level by drying and low temperature filtration.

\subsection{Viscosity}

The viscosity of oil needs to be low enough to ensure the oil flows under all temperature (particularly low) conditions thus providing necessary cooling and arc quenching.

\subsection{Breakdown Strength Test}

Breakdown test are normally conducted using test cells. For testing pure liquids, the test cells used are small so that less quantity of liquid is used during testing. The electrodes used for breakdown voltage measurements are usually spheres of $10 \mathrm{~cm}$ to $20 \mathrm{~cm}$ in diameter with gap spacing of about $0.4 \mathrm{~cm}$ to $1 \mathrm{~cm}$. The gap is accurately controlled by using a micrometer. Sometimes parallel plane uniform field electrode systems are also used. Electrode separation is very critical in measurements with liquids and also the electrode surface smoothness and the presence of oxide films have a marked influence on the breakdown strength. The test voltages required for these tests are usually low, up to $100 \mathrm{kV}$, because of small electrode spacing. The breakdown strengths is obtained in pure liquid of the order of $40 \mathrm{KV} / 4 \mathrm{~mm}-100 \mathrm{KV} / 4 \mathrm{~mm}$.

\section{Ageing Diagnosis of Power Transformer Using Fuzzy Logic}

\subsection{Overview of Fuzzy Logic}

A fuzzy expert system is an expert system that uses a collection of fuzzy membership functions and rules, instead of Boolean logic, to reason about data. The rules in a fuzzy expert system are usually of a form similar to the following: If $\mathrm{x}$ is low and $\mathrm{y}$ is high then $\mathrm{z}=$ medium where $\mathrm{x}$ and $\mathrm{y}$ are input variables (names for know data values), $\mathrm{z}$ is an output variable (a name for a data value to be computed), low is a membership function (fuzzy subset) defined on $x$, high is a membership function defined on $y$, and medium is a membership function defined on $z$. The antecedent (the rule's premise) describes to what degree the rule applies, while the conclusion (the rule's consequent) assigns a membership function to each of one or more output variables. Most tools for working with fuzzy expert systems allow more than one conclusion per rule. The set of rules in a fuzzy expert system is known as the rule base or knowledge base. The block diagram of fuzzy system is like this (See Figure 1).

Inputs Fuzzification Inference Defuzzification Output Knowledge Base Rule Base. The general inference process proceeds in four steps. 1) FUZZIFICATION: Under

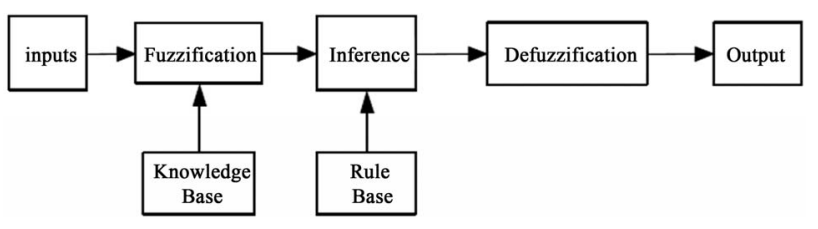

Figure 1. Block diagram of typical fuzzy logic system and the general inference process. 
fuzzyfication the membership functions defined on the input variables are applied to their actual values, to determine the degree of truth for each rule premise. 2) INFERENCE: Under inference, the truth value for the premise of each rule is computed, and applied to the conclusion part of each rule. This results in one fuzzy subset to be assigned to each output variable for each rule. Usually only MIN or PRODUCT is used as inference rules. In MIN inference, the output membership function is clipped off at a height corresponding to the rule premise's computed degree of truth (fuzzy logic AND). In PRODUCT inference, the output membership function is scaled by the rule premise's computed degree of truth. 3) COMPOSITION: Under composition, all the fuzzy subsets assigned to each output variable are combined together to form a single fuzzy subset for each output variable. Again, usually MAX or SUM is used. In MAX composition, the combined output fuzzy subset is constructed by taking the point wise maximum over all of the fuzzy subsets assigned to variable by the inference rule (fuzzy logic OR). In SUM composition, the combined output fuzzy subset is constructed by taking the point wise sum over all of the fuzzy subsets assigned to the output variable by the inference rule. 4) DEFUZZIFICATION: Finally the (optional) defuzzification is used when it is useful to convert the fuzzy output set to a crisp number. There are more defuzzification methods than you can shake a stick (at least 30). Two of the more common techniques are the CENTROID and MAXIMUM methods. In the CENTROID method, the crisp value of the output variable is computed by finding the variable value of the center of gravity of the membership function for the fuzzy value. In the MAXIMUM method, one of the variable values at which the fuzzy subset has its maximum truth value is chosen as the crisp value for the output variable. Presence of moisture, dissolved particles, acidity, resistivity and viscosity has serious impact on the asset performance and life, ignoring one could mislead the estimation. The fuzzy logic modeling and analysis has been carried out to get better asset's remnant life estimation. Figure 2 represents FIS editor showing 5-input variables and 1output variable, Figure 3-7 represents the moisture, particle size, acidity, resistivity and viscosity represents membership function plot for input variable Figure 8 represents the membership function plot for output variable age and Figure 9 represents the rule view of input and output variable.

\section{Results}

Developed algorithms have been used to evaluate the residual life of 40 MVA, 132/33 kV power transformer. Five tests have been conducted on three samples which were collected on different dates and tested on respective dates. Conducted tests results are shown in Table 1. In fuzzy system triangular membership function has been used [10,11]. Table 2 shows life of the transformer is evaluated in single stroke using developed fuzzy logic algorithm and obtained results have been compared with well established BDV test on transformer oil for breakdown strength. Table 1: Tests conducted on three samples of transformer oil Table 2: Residual life of the transformer evaluated using fuzzy-logic.

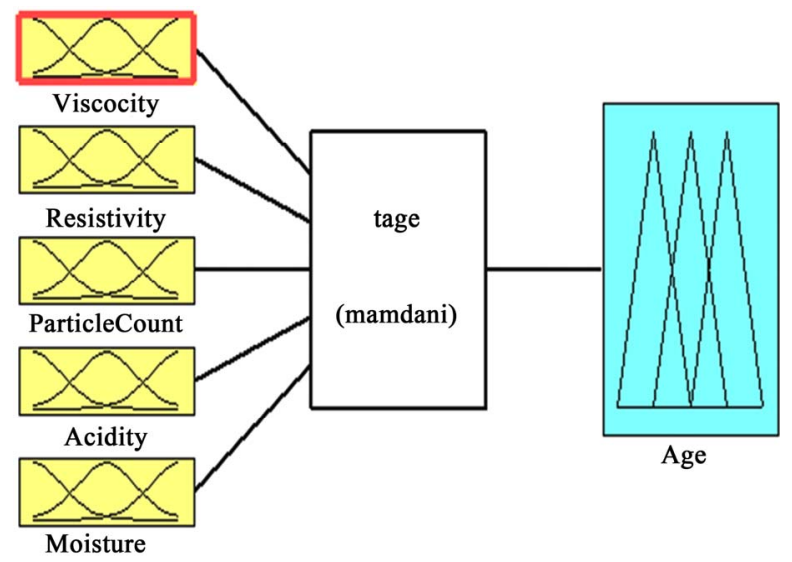

Figure 2. FIS Editor showing 5-input variables and 1-output Variable.

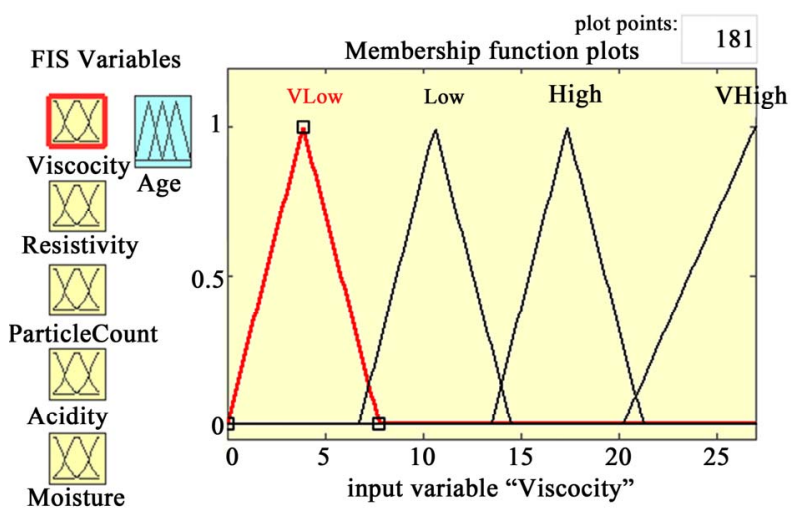

Figure 3. FIS Editor Showing membership function plot of viscosity.

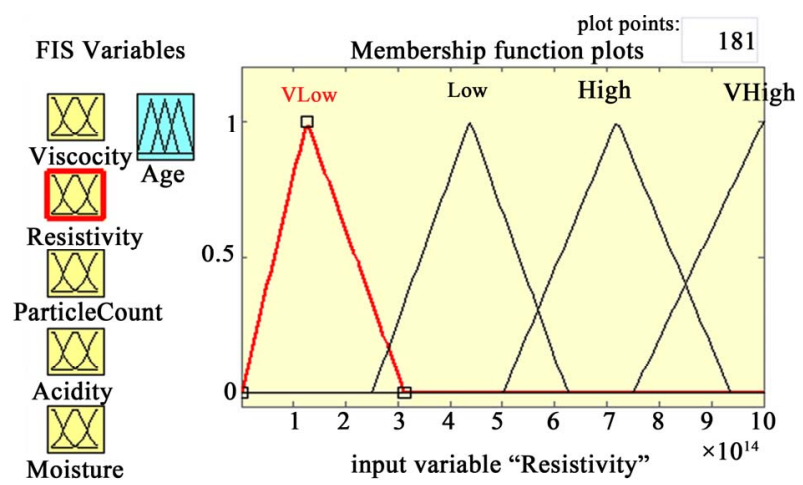

Figure 4. FIS Editor showing membership function plot of resistivity. 


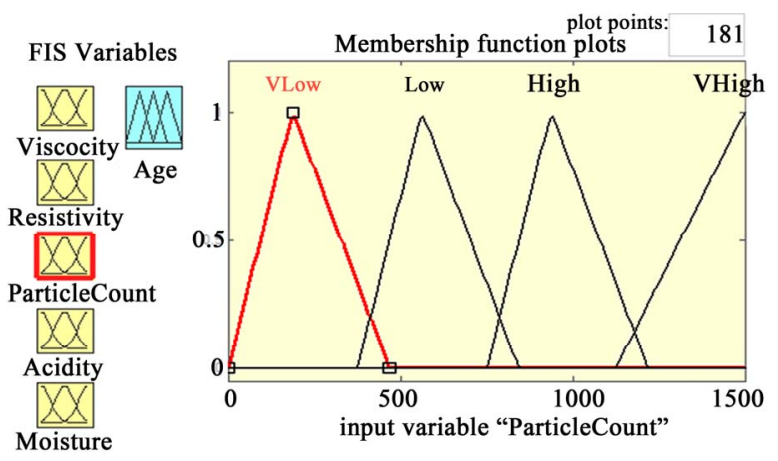

Figure 5. FIS showing membership function plot of size.

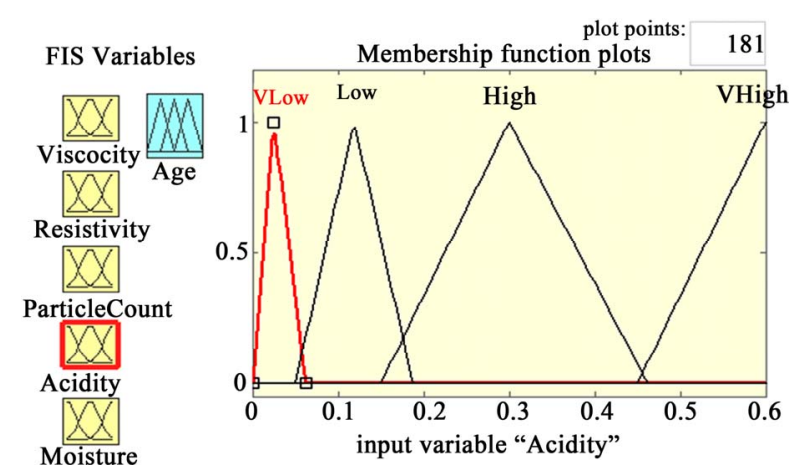

Figure 6. FIS Editor showing membership function plot for acidity.

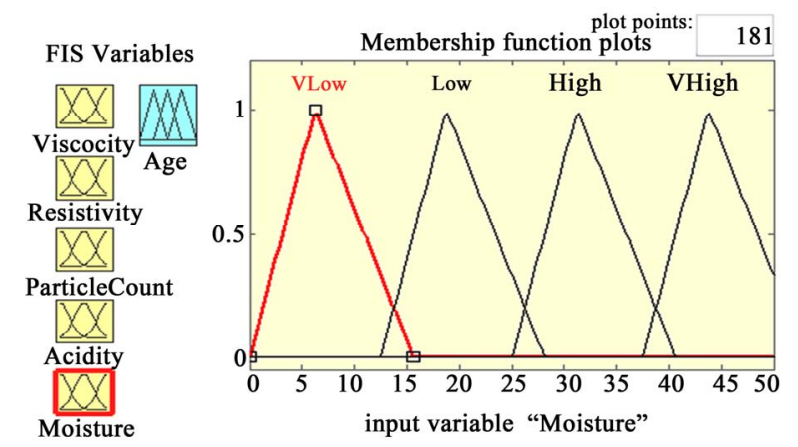

Figure 7. FIS Editor showing membership function plot for moisture.

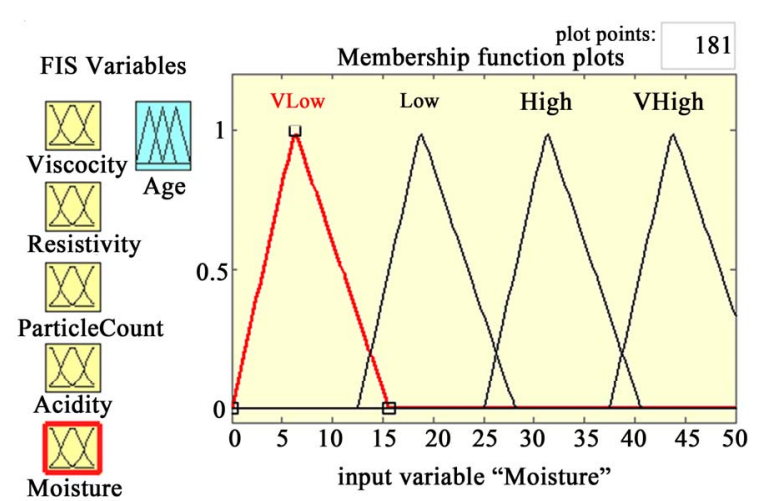

Figure 8. FIS Editor showing membership function plot for output variable age.

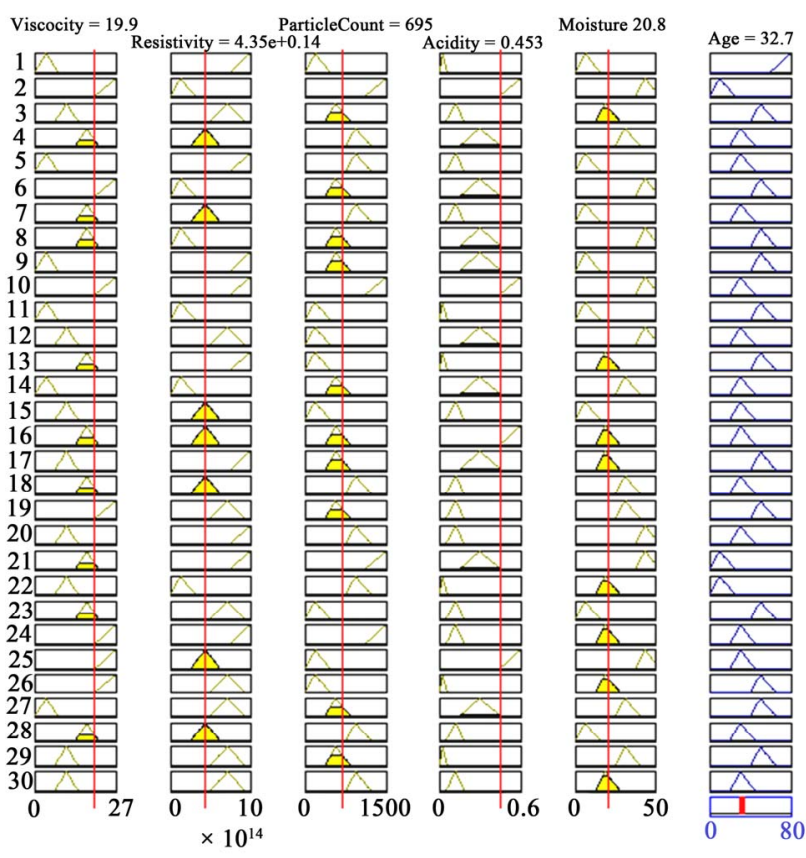

Figure 9. Showing the rule view of input and output variable.

Table 1. Tests conducted on three samples of transformer oil.

\begin{tabular}{lccc}
\hline Test & $\begin{array}{c}\text { First oil sample } \\
\text { collected on } \\
\text { 05 May 2010 } \\
\text { Testing results }\end{array}$ & $\begin{array}{c}\text { Second oil sample } \\
\text { collected on } \\
\text { 25 July 2010 } \\
\text { Testing results }\end{array}$ & $\begin{array}{c}\text { Third oil samp } \\
\text { collected on } \\
\text { 09 November } \\
\text { 2010 } \\
\text { Testing result }\end{array}$ \\
\hline $\begin{array}{l}\text { Moisture } \\
\text { content test }\end{array}$ & $45 \mathrm{ppm} / \mathrm{cc}$ & $28 \mathrm{ppm} / \mathrm{cc}$ & $35 \mathrm{ppm} / \mathrm{cc}$ \\
& & & \\
& & & \\
Acidity test & $0.04 \mathrm{mg}$ & $0.02 \mathrm{mg}$ & $0.03 \mathrm{mg}$ \\
& $\mathrm{KOH} / \mathrm{G}$ & $\mathrm{KOH} / \mathrm{G}$ & $\mathrm{KOH} / \mathrm{G}$
\end{tabular}

$\begin{array}{lccc}\begin{array}{l}\text { Particle } \\ \text { count test }\end{array} & 882 \mathrm{ppm} & 281 \mathrm{ppm} & 267 \mathrm{ppm} \\ \begin{array}{lcc}10.12 \\ \text { Restivity test }\end{array} & \begin{array}{c}10.10 \\ \text { ohm-cm }\end{array} & \begin{array}{c}10.11 \\ \text { ohm-cm }\end{array} \\ \begin{array}{l}\text { Flash point and } \\ \text { fire point test }\end{array} & 135^{\circ} \mathrm{C} & 121^{\circ} \mathrm{C} & 115^{\circ} \mathrm{C} \\ & & & \\ \text { Viscosity test } & 21 \mathrm{cst} & 12 \mathrm{cst} & 17 \mathrm{cst}\end{array}$


Table 2. Residual life of the transformer evaluated using fuzzy-logic.

\begin{tabular}{ccc}
\hline Samples & $\begin{array}{c}\text { Residual life } \\
\text { of the transformer } \\
\text { evaluated using } \\
\text { fuzzy logic }\end{array}$ & $\begin{array}{c}\text { Breakdown } \\
\text { strength evaluated } \\
\text { by BDV test }\end{array}$ \\
\hline $\begin{array}{c}\text { First oil sample } \\
\text { collected on 05 } \\
\text { May 2010 } \\
\text { Testing results }\end{array}$ & 47.5 years & \\
Second oil sample \\
collected on 25 \\
July 2010 \\
Testing results \\
\\
$\begin{array}{c}\text { Third oil sample } \\
\text { collected on 09 } \\
\text { November 2010 } \\
\text { Testing results }\end{array}$ \\
\end{tabular}

\section{Conclusion}

The transformer life is extended, and the risks are eliminated by residual life assessment. The user in meeting system demand, satisfactory operation of large power transformers can be achieved only if the condition of the coolant oil is maintained. Considerable experience exists worldwide where lack of attention to oil condition has led to shorter operational lives. Moisture is the most dangerous contaminant of insulating oils. As small as ten parts per million by volume can lower the dielectric strength of the oil below its acceptable value. The resistivity of a liquid is a measure of its electrical insulating properties under conditions comparable to those of the test. High resistivity reflects low content of free ions and ion-forming particles and normally indicates a low concentration of conductive contaminants. High acidity leads to advanced degradation and sludge formation. This in turn can lead to power cooling conditions and higher temperature leading to shorter lives. The viscosity of oil needs tobe low enough to ensure the oil flows under all temperature (particularly low) conditions. The oil must have a low Particle Size and count and low fiber content as the presence of such contaminants, especially in the presence of moisture, can considerably reduce the electric strength. The life estimation model of transformer presented here with the use of fuzzy logic controller. The fuzzy method has been proposed in this work due to its simplicity and accuracy.

\section{REFERENCES}

[1] J.-D. Cal and T. Zhang, "Moisture Content Assessment of Transformer Solid Insulation using Return Voltage Spectrum," Proceedings of the 26th Annual International Conference on Properties and Applications of Dielectric Materials, Harbin, 19-23 July 2009, pp. 257-260. doi:10.1109/ICPADM.2009.5252457

[2] B. García, J. C. Burgos, Á. M. Alonso and J. Sanz, “A Moisture-in-Oil Model for Power Transformer Monitoring-Part II: Experimental Verification,” IEEE Transaction on Power Delivery, Vol. 20, No. 2, 2005, pp. 1423-1429. doi:10.1109/TPWRD.2004.832361

[3] V. Mentlík, P. Prosr, R. Polanský, J. Michalík and M. Brandt "Instruments for Online Monitoring of Transformers," International Conference on Renewable Energies and Power Quality, Valencia, 15-17 April 2009, pp. 1-5.

[4] M. Mirzaie, A. Gholami and H. R. Tayebi, "Insulation Condition Assessment of Power Transformers Using Accelerated Ageing Tests,” Turkish Journal of Electrical Engineering and Computer Sciences, Vol. 17, No. 1, 2009, 39-54.

[5] D. Ming, Z. M. Ge, Q. Y. Ming and Y. Zhang "Ageing Diagnosis and Lifetime Estimation for Power Transformer," Proceeding of the 14th International Symposium on High Voltage Engineering, Beijing, 25-29 August 2005, pp. 1-5.

[6] H.-Z. Ding, Z. D. Wang and P. Jarman, "Dielectric Strength of Aged Transformer Oil Experimental Studies and Statistical Analysis of Breakdown Voltage," Proceeding of the 14th International Symposium on High Voltage Engineering, Beijing, 25-29 August 2005, pp. 1-5.

[7] H. P. Gasser, B. Heinrich and C. Krause "Condition Assessment of the Cellulosic Insulation from Power Transformer Taken out for Service," Proceeding of the 14th International Symposium on High Voltage Engineering, Beijing, 25-29 August 2005, pp. 1-5.

[8] M. Butcher, M. D. Cevallos and H. Krompholz, "Conduction and Breakdown Mechanisms in Transformer Oil," IEEE Transaction on Plasma Science, Vol. 34, No. 2, 2006, pp. 467-475. doi:10.1109/TPS.2006.872487

[9] M. Arshad, S. M.Islam and Abdul Khalique, "Power Transformer Aging and Life Extension,” 8th International Conference on Probabilistic Methods Applied to Power Systems, Ames, 12-16 September 2004, pp. 498-501.

[10] V. Duraisamy, N. Devarajan, D. Somasundareswari, A. A. M. Vasanth and S. N. Sivanandam, "Neuro Fuzzy Schemes for Fault Detection in Power Transformer," Applied Soft Computing, Vol. 7, No. 2, 2007, pp. 534-539. doi:10.1016/j.asoc.2006.10.001

[11] W. C. Floresa, E. Mombello, J. A. Jardinic and G. Rattá, "Fuzzy Risk Index for Power Transformer Failures Due to External Short-Circuits," Electric Power Systems Research, Vol. 79, No. 4, 2009, pp. 539-549. doi:10.1016/j.epsr.2008.06.021 